\title{
DESIGN AND NUMERICAL SIMULATION OF THE NEW DESIGN OF THE GRIPPER FOR MANIPULATING OF THE ROTATIONAL PARTS
}

\author{
Yevheniia BASOVA ${ }^{1}$, Kosta NUTSUBIDZE $^{2}$, Maryna IVANOVA ${ }^{3}$, \\ Serhii SLIPCHENKO ${ }^{4}$, Alexey KOTLIAR ${ }^{5}$
}

National Technical University «Kharkov Polytechnic Institute», Department of Technology of Mechanical
Engineering and Metal-Cutting Machine Tools, 2, Kyrpychova str., 61002, Kharkov, Ukraine
1 e-mail: e.v.basova.khpi@ gmail.com; ${ }^{2}$ e-mail: begemot9473@ gmail.com;
3e-mail: ivanovamaryna1@ @mail.com, ${ }^{4}$ e-mail: serg.slip@ @mail.com; ${ }^{5}$ e-mail: Alexeykotliar@gmail.com

Abstract

The analysis of the field of application of gripper is carried out. Are allocated perspective areas of development of a robotics. The main difficulties in the application of kinematic schemes for gripping devices with rotary finger movement are described. The prospective application of the kinematic scheme of the gripper with a straight-parallel plane-parallel motion of the fingers is proved when manipulating an object of the "shaft" type. A new scheme of a gripper with a rectilinear plane-parallel finger movement is presented. Its design is simpler and cheaper than known devices of this type. The capability of the gripper design in the engineering analysis environment has been fulfilled. Numerous computer studies of both individual design elements and pairs of objects that are in interaction have confirmed the operability of the developed design. It is established that the frictional force in the mobile components of the gripper design is insignificant, which will not create the prerequisites for a significant increase in size.

Keywords: gripper, kinematics, computer analysis, reliability

\section{INTRODUCTION}

Modern industry and competitive production should ensure product quality and productivity. Thus, increasing the requirements to the quality of products strengthens the relevance of the introduction of modern digital technologies. Industry introduce mechatronic robotic systems in production primarily to increase their own profits by reducing labor. This causes a constant search for technological solutions for the development and justification of modern optimized capture system. An analysis of the multifold of modern machinebuilding products has showed that about $30 \%$ of the production in Europe is corresponded for by the products of shaft-type parts from 30 to $80 \mathrm{~mm}$ in diameter. That is why the task aimed at developing and justifying the optimal gripping mechanism design for manipulating the "Shaft" part in a competitive production environment is topical.

The modern industry needs the use of unbeatable manipulators and robotic arms and grippers with promising solutions in both the form of closure and force closure $[1,2]$. The task of the gripping unit is the safe and accurate interaction with the environment while simultaneously contacting the object corresponding to the nature of the behaviour of the human hand [3].

\section{ANALYSIS OF INFORMATION SOURCES}

The development of modern gripping units is implemented by both industry and research groups [4-6]. Robotization is one of the priority areas for the development of competitive manufactures. An analysis of the researchers works had made it possible to determine the directions of modern developments.

In paper [7] gives a survey about forms of human-machine cooperation in assembly and available technologies that support the cooperation.

In paper [8] presented keynote which starts with a classification of grasping phases, describes how different principles are adopted at different scales in different applications and continues explaining different releasing strategies and principles.

The authors of the paper [9] presented a detailed work aimed at substantiating the application of various systems of capture and the principles of their management.

In research [10] presents the comparison between serial and parallel manipulators. It was noted that the parallel manipulator can be defined as a closed loop kinematic chain mechanism whose end effector is linked to the base by several independent kinematic chains. The classification of various parallel manipulators is presented herewith.

In work [11] was presented the advantages and disadvantages of robot-assisted spinal surgery, 
as well as the most common applications and different types of robots used for spinal surgery.

In review [12] aims to summarize the current state of the art from the heterogeneous range of fields that study the different aspects of these problems specifically in dual arm manipulation.

In [13], a review of space robots was discussed.

However, the analysis showed that most of the works has a review type. Existing solutions, in most cases, have an overpriced value, and information about their construction is presented in the aspect of advertising. In addition, the information provided excludes a deep analysis of the device design regarding its capabilities.

The target of the presented work is to develop and substantiate the expediency of using a new design of a gripping unit for manipulation a type of "shaft" object.

\section{MATERIAL AND METHODS}

3.1. Justification of the perspective of developing a new constructive decision of the gripping device

We have analyzed kinematic schemes of robots and manipulators that are used in the manufacture of rotational bodies [14]. It has been established that at least $60 \%$ of the variety of decisions is gantry-type robot. In fig. 1 shows a typical solution to this robot manipulator.

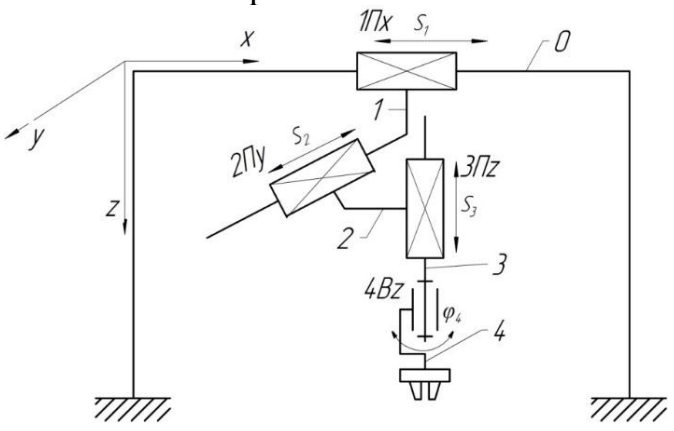

Fig. 1. Kinematic scheme of gantry-type robot for manipulating the object "shaft"

Such the robot manipulator is a complex mechanical system. The gripping device have to be a reliable and functional element that provides accurate and reliable retention of the object during manipulation and transport between the processing operations.

During the analysis and constructional design of the gripping devices of industrial robots have to take into account many factors that affect their functionality: the shape of the part, the parts properties, the technological process, and so on [1517]. We have studied the basic requirements for gripping devices. Also, the analysis of the most widely used kinematic schemes of gripping devices was carried out by us. As a result, we have found that existing constructive solutions may not always provide reliable manipulation by object. The cause for this is that the object of manipulation, as a rule, changes its geometric dimensions in the passing of technological operations. It follows that the use of circuits with rotational movements of the fingers, when the tops of the fingers move along the arc of the circle, and the position of the gripper center depends on the angle of inclination of the output link of the transmission mechanism, is problematic. The reason for this is the offset of the gripping device center depending on the size of the object. In turn, this will lead to a complication of the programming code for robot running. In this way, we have concluded that the use of a circuit with straight-line plane-parallel motion of fingers is potentially productive. However, design solutions based on well-known circuits with liner planeparallel finger movements are too complex and have a large number of movable elements (toothed rails, gear wheels). This as a result increases the design of the gripping device.

\subsection{Development of the design of the gripping device with liner plane-parallel movement of the fingers}

The result of the search for a new constructive solution for the development of a schematic of a gripping device with liner plane-parallel movement of the fingers was the scheme which is presented in Fig.2. An analogue of the projected mechanism was the cam chuck of a metal cutting machine. The peculiarity of the design is the simplicity and the possibility of self-centering of the part in two planes (Fig.4d). The principle of this device is as follows: the wedge (position 1) moves downwards from the force of the drive (not shown in the figure), thereby pulling the drive lug (position 2) to the center. The drive lug is connected to the wedge through the T-groove and the interaction system of the objects moves along the slide guides. On the drive lug, the cams (item 3) are stiffly fixed, which have prismatic working surfaces for fixing cylindrical parts.

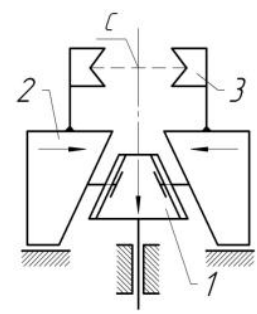

Fig. 2. Kinematic scheme of the gripping device:

1 - wedge; 2 - drive lug; 3 - cam; c - grasping center point

In accordance with the above, we will highlight the competitive advantages of this solution - a small number of elements and the independence of the center of the gripping device from the size of the part.

It should be noted that from the wedge movement will depend on the overall dimensions and mass of the gripping device, so for the construction of the design, it is necessary to reasonably choose the optimal ratio of the wedge movement and the cam movement (Fig. 3). 


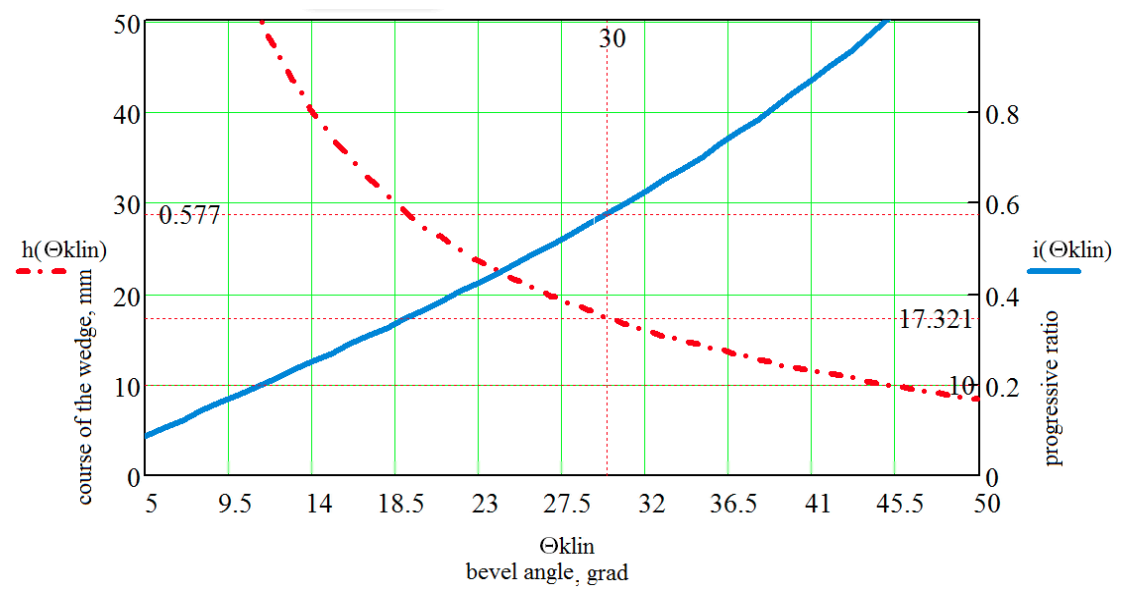

Fig. 3. The graph of the dependence of the ratio $i$ on the angle of the wedge $\theta$ and the passage of the wedge from its angle $\theta(h(\theta)$ and $i(\theta))$

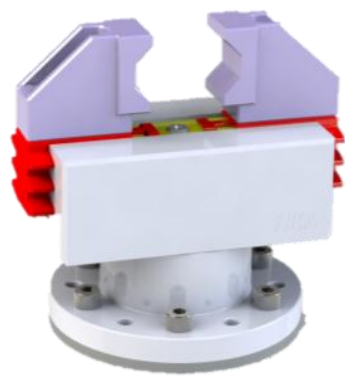

a

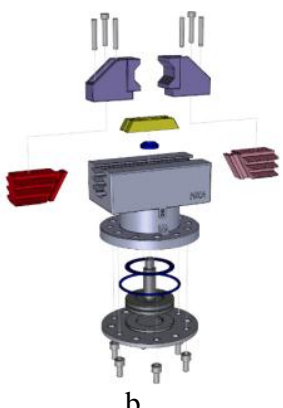

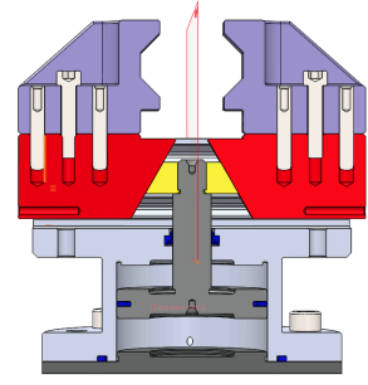

c

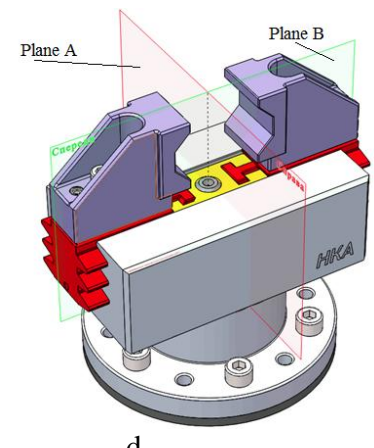

d

Fig. 4. Model of projected gripper: a - solid-state model, b - components of the model, c - model in the section

From Fig. 3 it can be seen that with the increase of the wedge angle $\theta$, the wedge movement $h$ is reduced, with the gear ratio of the gripping device increasing.

The results of computing and constructive solutions were our representation of the solid model of the projected gripping device (Fig. 4).

The computing model has the following characteristics:

- gripping force - $1700 \mathrm{~N}$;

- $\quad$ one cam movement - $10 \mathrm{~mm}$;

- nominal pressure of the operating environment (air) - 0,4 MPa.

Work cams can be changed, this will increase the range of shaft diameters for manipulation.

During running, such a design should ensure the reliability of the complete mechanism.

However, it should be noted that in the gripping device the drive lug and the wedge will operate under constant friction relative to each other.

It is also possible to get dirt on the friction surface, therefore it is recommended to put the following requirement on wedge and drive lug material (Table 1).

Therefore, we have carried out numerous computer experiments in the SolidWorks Simulation integrated module, which have allowed us to optimize the design and assert that it is reliable and advanced.
Table 1. Requirements for wedge and drive lug material

\begin{tabular}{|l|l|l|}
\hline \multicolumn{3}{|c|}{ The main requirements for the material of the elements } \\
of the gripping device design
\end{tabular}

\section{RESULTS AND DISCUSSION}

To optimize and substantiate the operability of the designed structure, we used analysis based on the finite element method. The task was to test the following conditions for the operation of composite units and the structure as a whole [18]:

- dimensional characteristics and strength characteristics of the elements;

- the likelihood of swashs in the wedges when using the gripping device;

- Investigations of friction in guidewais and wedge.

As a result of a number of static computational investigation, it was determined that the elements of the designed construction satisfy the reliability requirements of the mechanism (Fig. 5, Table 2). 
The von Mises stress (Fig. 5) or equivalent stress is the stress value calculated from the stress components. Despite the fact that the equivalent stress at any point determines the state of the stress at this point is ambiguous, it provides information sufficient to evaluate the reliability of the design for many plastic materials.

The von Mises stress is calculated as follows on the basis of six stresses components (1):

$V O N=\left\{\begin{array}{l}\left.0,5 \cdot\left[(S X-S Y)^{2}+(S X-S Z)^{2}+(S Y-S Z)^{2}\right]+\right\}^{\left(\frac{1}{2}\right)}(1) \\ +3 \cdot\left(T X Y^{2}+T X Z^{2}+T Y X^{2}\right)\end{array}\right\}^{(1)}$

Or, equivalently, based on the three main stresses

$$
V O N=\left\{0,5 \cdot\left[\left(P_{1}-P_{2}\right)^{2}+\left(P_{1}-P_{3}\right)^{2}+\left(P_{2}-P_{3}\right)^{2}\right]\right\},
$$

where

$\mathrm{SX}$ - direct stress on the axis $\mathrm{X}$;

SY - direct stress on the axis Y;

$\mathrm{SZ}$ - direct stress on the axis $\mathrm{Z}$;

TXY - Y intercept in the YZ plane;

TXZ - Z intercept in the YZ plane;

$\mathrm{TYZ}-\mathrm{Z}$ intercept in the $\mathrm{XZ}$ plane;
$\mathrm{P}_{1}-1$ main stress (highest), does not use the reference value:

$\mathrm{P}_{2}-2$ main stress, does not use the reference value; $\mathrm{P}_{3}-3$ main stress, does not use the reference value.

Thus, we analyzed the total stresses that occur with the maximum load of the structural elements (Fig. 6). It is established that the static total stresses do not exceed the maximum permissible stresses taking into account the safety factor According to the recommendations given above (Table 2), the material for the execution of the components of gripping device was assigned (Table 3 ). From the results of the research it is evident that the maximum stresses that have arisen in the places of the greatest concentration of applied force are permissible for each of the constituent elements. Investigation of the plastic flow of the elements has shown that the maximum value of such characteristic varies from $1 \mu \mathrm{m}$ to $6 \mu \mathrm{m}$. It should be noted that, within the limits of the accuracy of the product, such movement will not affect the normal operation of the gripping device (Table 3 ).
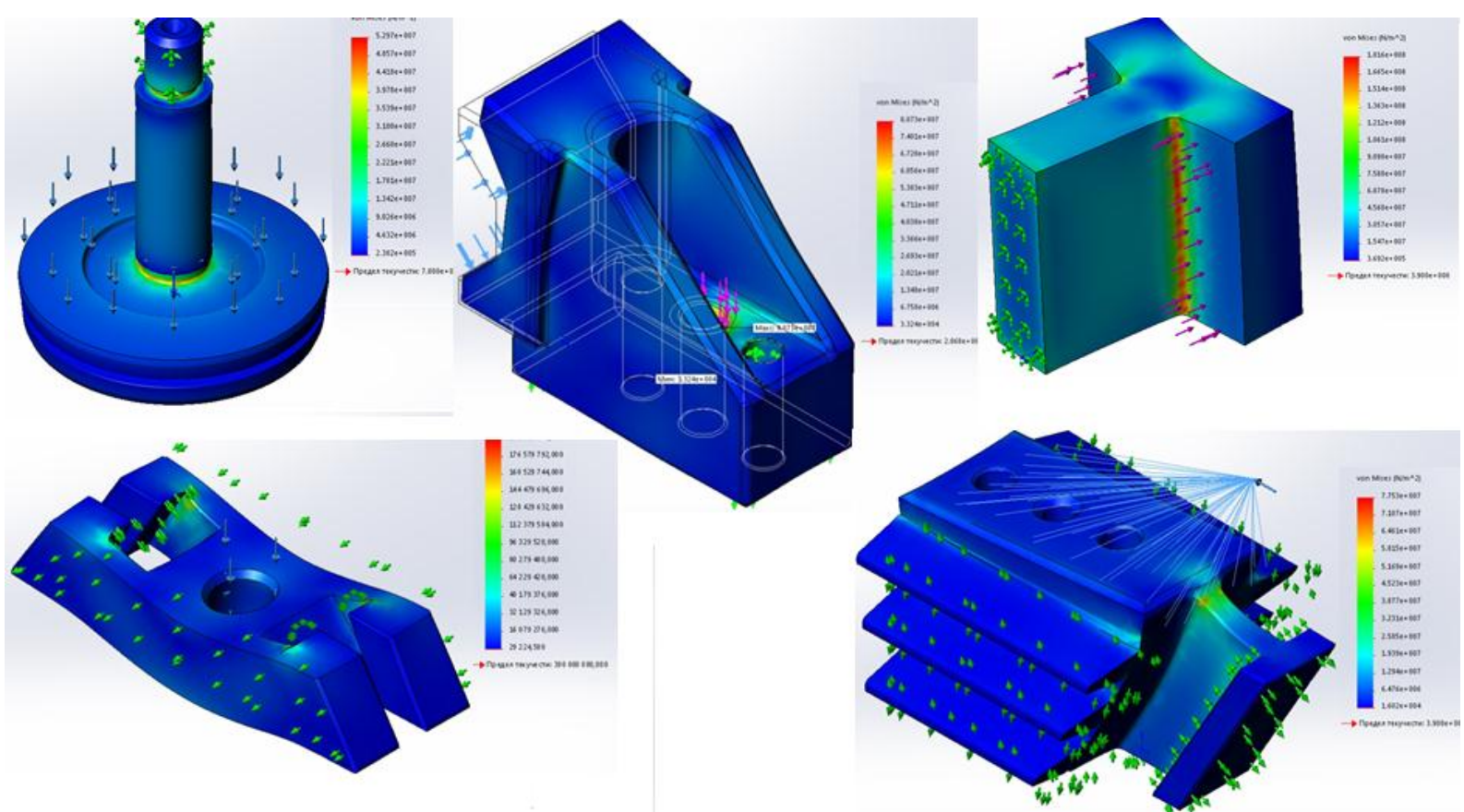

Fig. 5. Experimental study of the stress (von Mises stress) of structural elements for further optimization of its geometry

Table 2. The results of numerous experiments to determine the reliability of the constituent elements geometry of the

\begin{tabular}{|c|c|c|c|c|}
\hline Element / Material & $\begin{array}{l}\text { Static stress (Von } \\
\text { Mises stress) }\end{array}$ & $\begin{array}{l}\text { Resulting displacement } \\
\text { (plastic flow) }\end{array}$ & $\begin{array}{l}\text { Component of strain - } \\
\text { equivalent deformation } \\
\text { (ESTRN), mm }\end{array}$ & $\begin{array}{l}\text { Assurance } \\
\text { coefficient }\end{array}$ \\
\hline $\begin{array}{c}\text { Wedge / material } \\
\text { LH15 }\end{array}$ & $\begin{array}{c}\text { Min }=29.2 \mathrm{MPa} \\
M a x=192,6 \mathrm{MPA}\end{array}$ & $\begin{array}{l}\operatorname{Min}=2 \text { мкм } \\
\text { Max }=5 \text { мкм }\end{array}$ & $\begin{array}{l}\text { Min }=0,0000 \\
\operatorname{Max}=0,0007\end{array}$ & $\begin{array}{l}\mathrm{Min}=2.025 \mathrm{e}+000 \\
\mathrm{Max}=1.334 \mathrm{e}+004\end{array}$ \\
\hline $\begin{array}{l}\text { Jaw/ material } \\
\text { D } 35\end{array}$ & $\begin{array}{c}\text { Min }=0,03 \mathrm{MPa} \\
\operatorname{Max}=80,73 \mathrm{MPA}\end{array}$ & $\begin{array}{l}\text { Min=0 мкм } \\
\operatorname{Max}=4 \text { мкм }\end{array}$ & $\begin{array}{c}\operatorname{Min}=0,00021 \\
\operatorname{Max}=0,24\end{array}$ & $\begin{array}{l}\mathrm{Min}=2.562 \mathrm{e}+000 \\
\mathrm{Max}=6.222 \mathrm{e}+003\end{array}$ \\
\hline $\begin{array}{c}\text { Drive lug/ material } \\
\text { LH15 }\end{array}$ & $\begin{array}{r}\mathrm{Min}=0,016 \mathrm{MPa} \\
\mathrm{Max}=77,53 \mathrm{MPA}\end{array}$ & $\begin{array}{l}\text { Min }=0.003 \text { мкм } \\
\text { Max }=1,14 \text { мкм }\end{array}$ & $\begin{array}{c}\text { Min }=0,0000 \\
\operatorname{Max}=0,003\end{array}$ & $\begin{array}{c}\text { Min }=5.030 \\
\text { Max=24 338,908 }\end{array}$ \\
\hline $\begin{array}{c}\text { Piston / Material } \\
40 \mathrm{H}\end{array}$ & $\begin{array}{r}\text { Min }=0,024 \mathrm{MPa} \\
\operatorname{Max}=52.97 \mathrm{MPA}\end{array}$ & $\begin{array}{l}\text { Min=0 мкм } \\
\operatorname{Max}=5 \text { мкм }\end{array}$ & $\begin{array}{l}\operatorname{Min}=1.537 \mathrm{e}-006 \\
\operatorname{Max}=1.544 \mathrm{e}-004\end{array}$ & $\begin{array}{l}\operatorname{Min}=1.473 \mathrm{e}+001 \\
\operatorname{Max}=3.274 \mathrm{e}+003\end{array}$ \\
\hline
\end{tabular}


Thus, the stiffness of the structure meets the reliability requirements.

Based on the received data, we concluded that the design of the components part and the material of their implementation completely satisfy the requirements for the operation of the projected device.

Equivalent deformation (ESTRN) is defined as:

$$
\text { ESTRN }=2 \cdot\left[\frac{\varepsilon_{1}+\varepsilon_{2}}{3}\right]^{\frac{1}{2}},
$$

where

$$
\begin{gathered}
\varepsilon_{1}=0,5 \cdot\left(\left(E P S X-\varepsilon^{*}\right)^{2}+\left(E P S Y-\varepsilon^{*}\right)^{2}+\left(E P S Z-\varepsilon^{*}\right)^{2}\right] ; \\
\varepsilon_{1}=0,5 \cdot \frac{\left[(G M X Y)^{2}+(G M X Z)^{2}+(G M Y Z)^{2}\right]}{4} ; \\
\varepsilon^{*}=\frac{(E P S X+E P S Y+E P S Z)}{3} ;
\end{gathered}
$$

where the strain components:

EPSX - normal strain along the $\mathrm{X}$ axis; EPSY - normal strain along the Y axis; EPSZ - normal strain along the $Z$ axis; GMXY - Y intercept in the YZ plane; GMXZ - Z intercept in the YZ plane;

$\mathrm{GMXZ}-\mathrm{Z}$ intercept in the $\mathrm{XZ}$ plane.

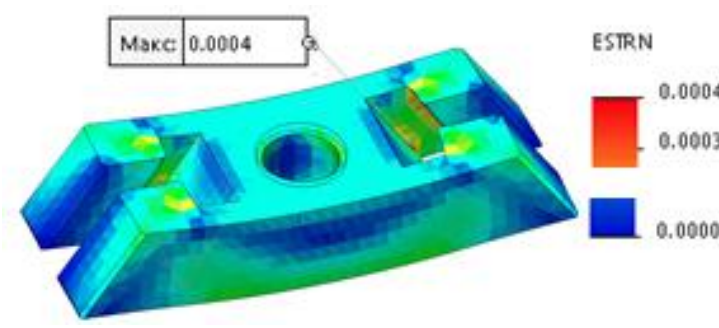

a

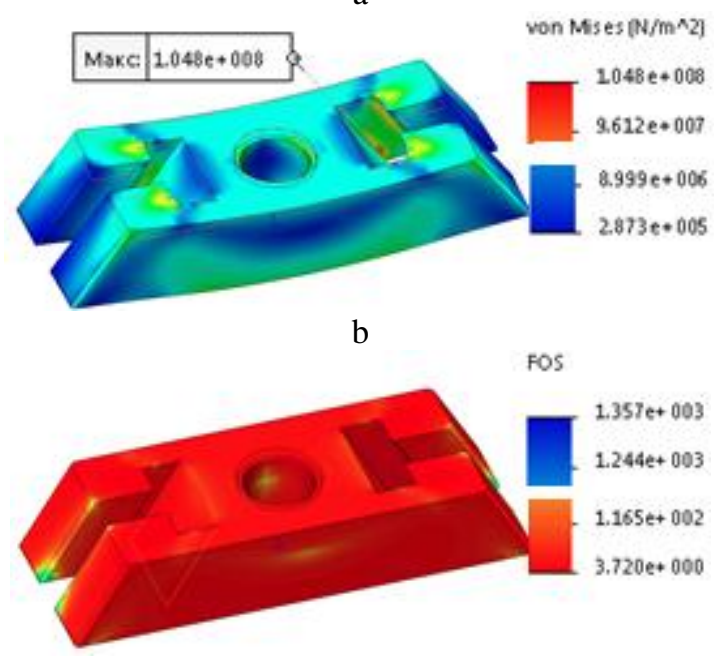

c

Fig. 6. Analysis of the construction to tilts in the wedges: a - wedge strain diagram; $\mathrm{b}$ wedge stress diagram (yield stress $\sigma_{\mathrm{ys}}=3,9 \cdot 10^{8}$ $\mathrm{N} / \mathrm{m}^{2}$ ); c - assurance coefficient diagram of the wedge (minimum assurance coefficient 3.7)

In accordance with the result of the study, we conclude that, with adequate normal rated load and optimal construction of the gripping device elements, the deformations of the wedge will be small, and their magnitude can be neglected.

At the next step of the projecting, we performed an analysis of the coupling of objects pairs systems:

- drive lug - wedge (Fig. 7);

- drive lug - shank guides (Fig. 8), (Table 3);

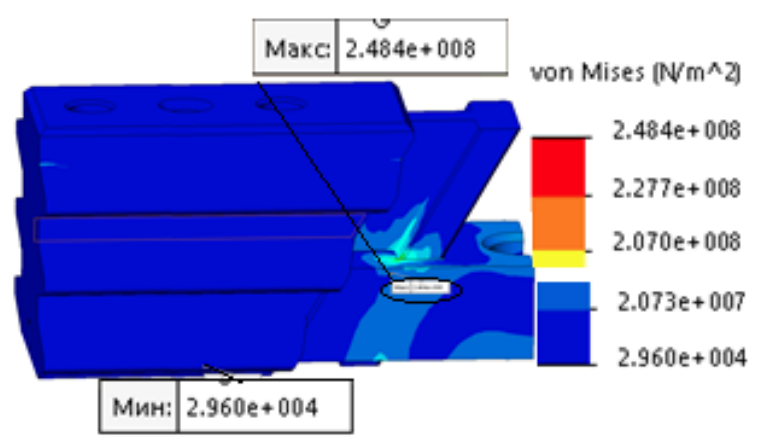
$\mathrm{a}$

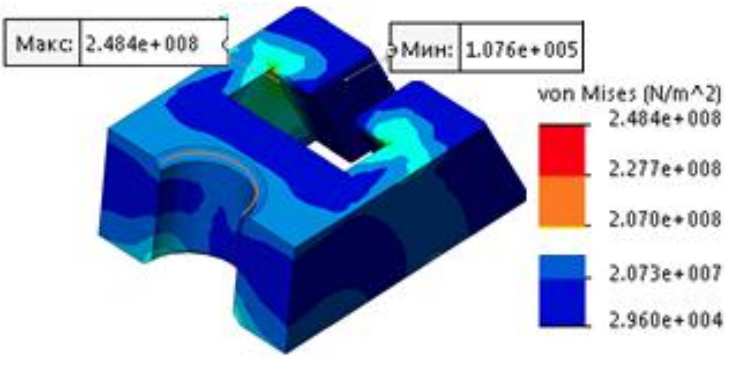
b
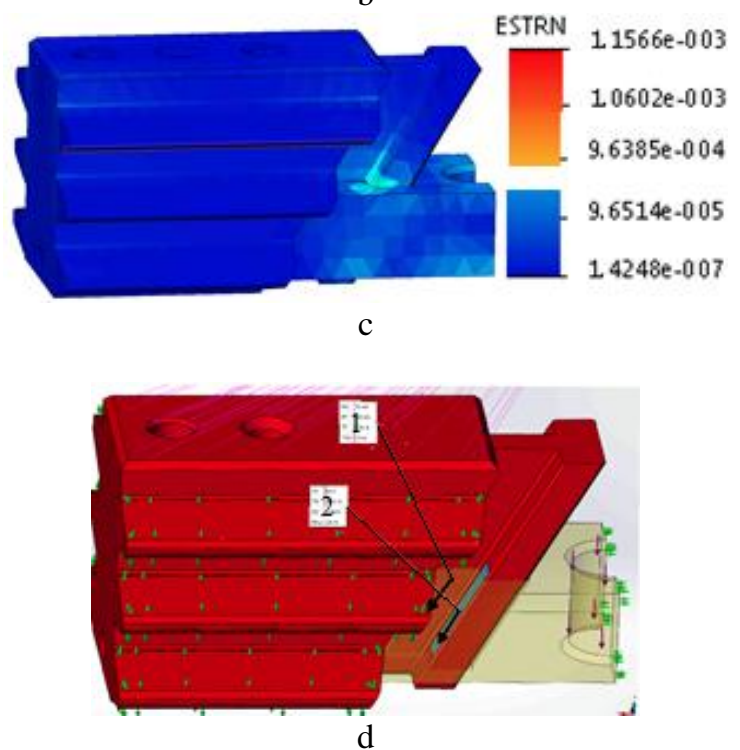

Fig. 7. Analysis of the coupling of objects pairs systems (drive lug - wedge): a, b - load diagram; c - strain diagram; $d$ - investigation of frictional force (1 $\mathrm{F}_{\text {res }}=100 \mathrm{~N}, 2-\mathrm{F}_{\text {res }}=111 \mathrm{~N}$ )

The conditions for the self-centering of the drive lugs of the gripping device were investigated. The results of the study confirmed the fulfillment of the task of self-centering while ensuring correct operating conditions for the mechanism (Fig. 9), (Tabl. 4) 

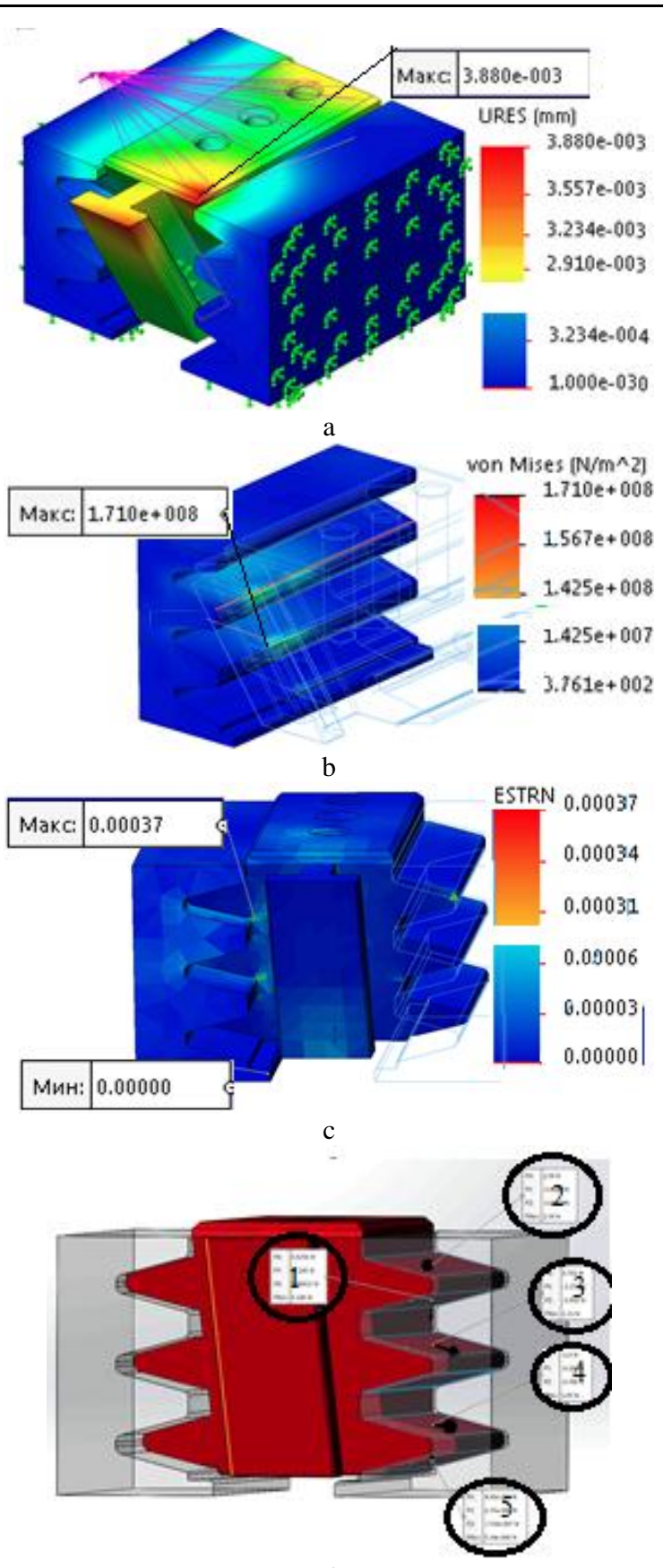

d

Fig. 8. Analysis of the coupling of objects pairs systems (drive lug - shank guides): $a$ - displacements profile; $b$ stress diagram; $\mathrm{c}$ - strain diagram; $\mathrm{d}$ - investigation of frictional force (Tabl. 3)

Table 3. The distribution of force in the designed structure under the condition of self-centering by applying of trapezoidal guides in the B plane

\begin{tabular}{|c|c|c|c|c|}
\hline \multirow{2}{*}{$\begin{array}{l}\text { Contact } \\
\text { position }\end{array}$} & \multicolumn{4}{|c|}{ Force distribution, $\mathrm{N}$} \\
\hline & Fx & Fy & $\mathrm{Fz}$ & Fres \\
\hline 1 & 0,0256 & $-0,143$ & 0,00832 & 0,146 \\
\hline 2 & 1,38 & $-0,0109$ & $-0,0407$ & 1,38 \\
\hline 3 & 0,781 & $-0,239$ & $-0,892$ & 1,21 \\
\hline 4 & $-1,8$ & $-0,104$ & $-0,388$ & 1,85 \\
\hline 5 & $4,99 \mathrm{e}-006$ & $1,75 \mathrm{e}-006$ & $-7,59 \mathrm{e}-007$ & $5,34 \mathrm{e}-006$ \\
\hline
\end{tabular}

Comprehensive research has been carried out.

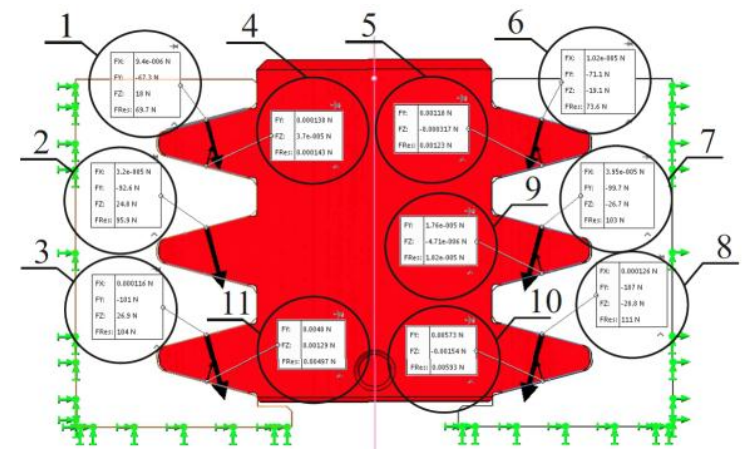

Fig. 9. Self-centering with trapezoidal guides in the B plane

Table 4. The distribution of force in the designed structure under the condition of self-centering by applying of trapezoidal guides in the $\mathrm{B}$ plane

\begin{tabular}{|c|r|r|r|r|}
\hline \multirow{2}{*}{$\begin{array}{c}\text { Contact } \\
\text { position }\end{array}$} & \multicolumn{5}{|c|}{ Force distribution, N } \\
\cline { 2 - 5 } & Fx & \multicolumn{1}{|c|}{ Fy } & \multicolumn{1}{c|}{ Fz } & \multicolumn{1}{c|}{ Fres } \\
\hline 1 & $9,4 \mathrm{e}-006$ & 67,3 & 18 & 69,7 \\
\hline 2 & $3,2 \mathrm{e}-005$ & $-92,6$ & 24,8 & 95,9 \\
\hline 3 & 0,000116 & -101 & 26,9 & 104 \\
\hline 4 & & 0,000138 & $3,7 \mathrm{e}-005$ & 0,000143 \\
\hline 5 & & 0,00118 & $-0,000317$ & 0,00123 \\
\hline 6 & $1,02 \mathrm{e}-005$ & $-71,1$ & $-19,1$ & 73,6 \\
\hline 7 & $3,95 \mathrm{e}-005$ & $-99,7$ & $-26,7$ & 103 \\
\hline 8 & 0,000126 & -107 & $-28,8$ & 111 \\
\hline 9 & & $1,76 \mathrm{e}-005$ & $-4,71 \mathrm{e}-006$ & $1,82 \mathrm{e}-005$ \\
\hline 10 & & 0,00573 & $-0,00154$ & 0,00593 \\
\hline 11 & & 0,0048 & 0,00129 & 0,00497 \\
\hline
\end{tabular}

To obtain a complete understanding of the interaction of the objects system of the proposed device, additional studies have been carried out (Fig. 10, Fig. 11).
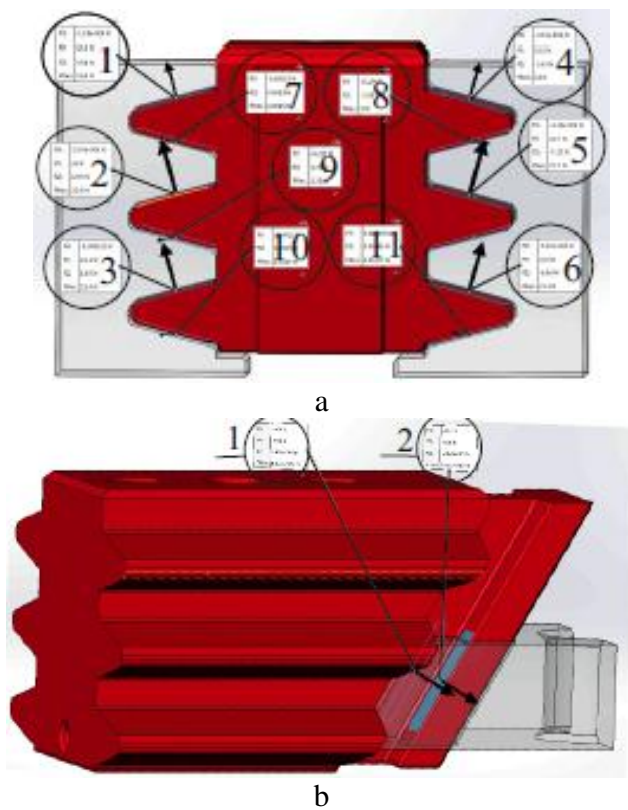

Fig. 10. Reaction of gripping device components during operation: a - reaction of slideway supports (Table 5); b - reaction of the wedge guide supports $\left(1-\mathrm{F}_{\mathrm{res}}=1,12 \mathrm{kN}, 2-\mathrm{F}_{\mathrm{res}}=1,01 \mathrm{kN}\right)$ 
Table 5. The distribution of the force components in the investigation of the reaction of slideway supports

\begin{tabular}{|c|c|r|r|r|}
\hline \multirow{2}{*}{$\begin{array}{c}\text { Contact } \\
\text { position }\end{array}$} & \multicolumn{5}{|c|}{ Force distribution, N } \\
\cline { 2 - 5 } & Fx & \multicolumn{1}{|c|}{ Fy } & \multicolumn{1}{c|}{ Fz } & \multicolumn{1}{c|}{ Fres } \\
\hline 1 & $2,28 \mathrm{e}-006$ & 13,2 & 3,54 & 13,6 \\
\hline 2 & $-5,07 \mathrm{e}-006$ & 26 & 6,97 & 26,9 \\
\hline 3 & $-0,000112$ & 21,1 & 5,67 & 21,8 \\
\hline 4 & $-2,13 \mathrm{e}-006$ & 13,5 & $-3,63$ & 14 \\
\hline 5 & $4,36 \mathrm{e}--006$ & 26,7 & $-7,17$ & 27,7 \\
\hline 6 & $-5,12 \mathrm{e}-006$ & 22,5 & $-6,06$ & 23,3 \\
\hline 7 & & $-0,00357$ & 0,0614 & 0,0615 \\
\hline 8 & & $-0,174$ & $-2,99$ & 3 \\
\hline 9 & & $-0,217$ & 1,23 & 1,25 \\
\hline 10 & & 0,0013 & 0,0215 & 0,0215 \\
\hline 11 & & 0,000299 & 0,00169 & 0,00172 \\
\hline
\end{tabular}

According to the results of the conducted research's it is necessary to revert that the frictional force in the removable components of the gripping device is insignificant. This result indicates that there is no prerequisite for a significant increase in the size of the drive.

Given the fact that the drive lug carries a large operational load, the strain analysis of the drive lug has been performed.

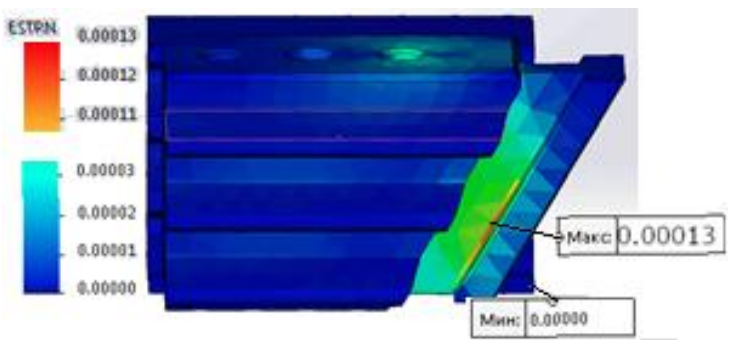

Fig. 11. Strain analysis of the drive lug

Researches have shown that the projected design has high operational properties and reliability.

\section{CONCLUSIONS}

Thus, using the capabilities of the CAE module of the SolidWorks Simulation to develop the optimal device design was justified. It is established that with variation by different engineering data, there is an absolute probability of finding the optimal model that allows to withstand the given loads.

A large number of complex computer researches both separate elements and objects pairs systems that are in cooperation have confirmed the operability and reliability of the developed device.

A further area of research for the projected gripping device involves the development of a clamping force monitoring system that will allow the design to be used when manipulating parts with reduced stiffness.

\section{REFERENCES}

1. Siciliano B, Khatib O. Springer Handbook of Robotics; Springer Science \& Business Media: Berlin/Heidelberg, Germany, 2008.

2. Kozyrev Yu G. The use of industrial robots. Tutorial. Publishing house "Prospekt" 2013. Rusian.

3. Monkman GJ, Hesse S, Steinmann R, Schunk H. Robot Grippers. John Wiley \& Sons: Weinheim, Germany, 2007.

4. Anna Maria Gil Fuster. Gripper design and development for a modular robot. DTU Electrical Engineering Automation and Control Technical University of Denmark. Denmark, 2015

5. Van de Ridder LW. Design and Control of an Underactuated Gripper Module for Interaction with a Remote Environment. Robotics and Mechatronics EE-Math-CS University of Twente. 2015

6. Koskinen K. Design of a smart gripper for industrial applications. Faculty Council of the Faculty of the Faculty of Engineering Sciences. Tampere University of technology. 2016

7. Krüger J, Lien TK, Verl A. Cooperation of human and machines in assembly lines. CIRP Ann. Manuf. Technol 2009; 58: 628-646. https://doi.org/10.1016/j.cirp.2009.09.009

8. Fantoni G, Santochi M, Dini G, Tracht K, ScholzReiter B, Fleischer J, Lien TK, Seliger G, Reinhart G, Franke J. Grasping devices and methods in automated production processes. CIRP Ann. Manuf. Technol. 2014; 63: 679-701.

https://doi.org/10.1016/j.cirp.2014.05.006

9. Staretu I. Gripping Systems. Derc Publishing House: Tewksbury. MA, USA 2011. http://www.imsar.ro/SISOM Papers 2013/SISOM 2 013_R_25.pdf

10. Patel YD, George PM, Parallel Manipulators Applications - A Survey. Mod. Mech. Eng. 2012; 2: 57-64. http://dx.doi.org/10.4236/mme.2012.23008

11. Hector Soriano-Baron, Eduardo Martinez-del-Campo, Neil R. Crawford NT. Robotics in Spinal Surgery: The Future is Here. Barrow Quarterly. 2016; 26(1): 34-38.

https://pdfs.semanticscholar.org/6c45/b3a2609e80e1e 31ddf383caadcec3fcc5ff1.pdf

12. Smith B, Karayiannidis Y, Nalpantidis L, Gratal X, Qi P, Dimarogonas DV, Kragic D. Dual arm manipulation - A survey. Robot. Auton. Syst. 2012; 60: $1340-1353$.

http://dx.doi.org/10.1016/j.robot.2012.07.005

13. Hirzinger G, Brunner B, Landzettel K, Schott J. Preparing a new generation of space robots - A survey of research at DLR. Robot. Auton. Syst. 1998; 23: 99-106.

14. Kozyrev YuG. Gripping devices and tools of industrial robots: a tutorial. Moscow 2010. Rusian.

15. Frolov KV. Mechanics of industrial robots: Textbook for high schools: Calculation and design of mechanisms. Moscow, Higher School 1988.Rusian.

16. Frolov KV. Mechanics of industrial robots: Textbook for high schools: Kinematics and dynamics. Moscow, Higher School 1988. Rusian.

17. Mechanics of industrial robots: Textbook for high schools: The basics of design. Moscow, Higher School 1989. Rusian. 
18. Finite Element Analysis in SolidWorks Simulation. Electronic resource.

http://cadregion.ru/solidworks-simulation/konechnoelementnyj-analiz-v-solidworks-simulation.html

Received 2018-04-17

Accepted 2018-08-07

Available online 2018-09-04

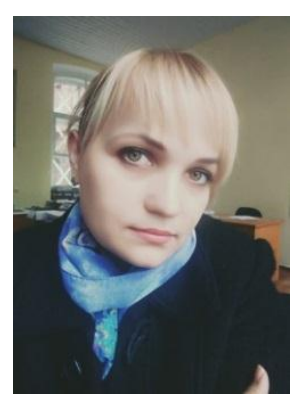

Yevheniia BASOVA (ORCID 0000-0002-8549-4788), PhD, Associate Professor at the Department of technology of mechanical engineering and metal-cutting machine tools of the Educational and scientific institute of mechanical engineering and transport of the NTU «KhPI», Kharkov, Ukraine. Main directions of scientific research: physicotechnical processing methods, engineering technology, programming, CAD / CAM / CAE / CAPP systems, optimization and modelling in mechanical engineering processes for technological prognostication in innovations.

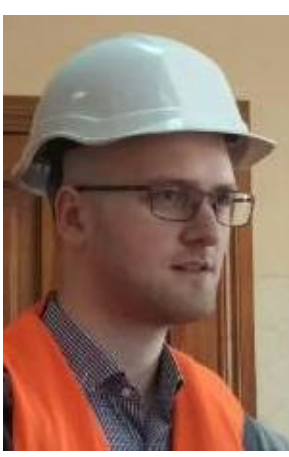

\section{Kosta NUTSUBIDZE} (ORCID 0000-0001-61415822), baccalaureate at the Department of technology of mechanical engineering and metal-cutting machine tools of the Educational and scientific institute of mechanical engineering and transport of the NTU «KhPI», Kharkov, Ukraine.

Main directions of scientific research: physicotechnical processing methods, engineering technology, applied mechanics, CAD / CAM / CAE / CAPP systems, optimization and modelling in mechanical engineering processes for technological prognostication in innovations.

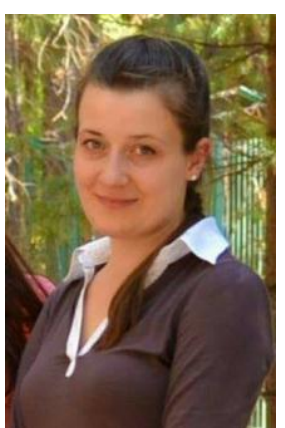

Maryna IVANOVA (ORCID 0000-0002-0848-6805), PhD, Associate Professor at the Department of technology of mechanical engineering and metal-cutting machine tools of the Educational and scientific institute of mechanical engineering and transport of the NTU «KhPI», Kharkov, Ukraine. Main directions of scientific research: enhancement of functional capabilities and an increase productivity metalcutting machines; multi-criteria optimization of technological processes and systems.

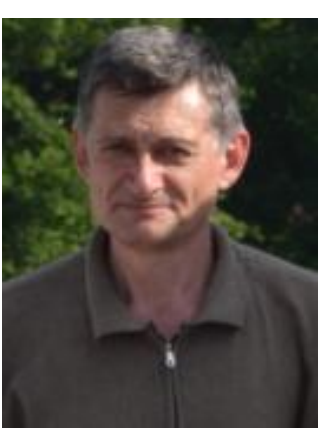

Serhii SLIPCHENKO (ORCID 0000-0003-05933750), Senior Lecturer at the Department of technology of mechanical engineering and metal-cutting machine tools of the Educational and scientific institute of mechanical engineering and transport of the NTU «KhPI», Kharkov, Ukraine.

Main directions of scientific research: enhancement of functional capabilities and an increase productivity metal-cutting machines; multicriteria optimization of technological processes and systems.

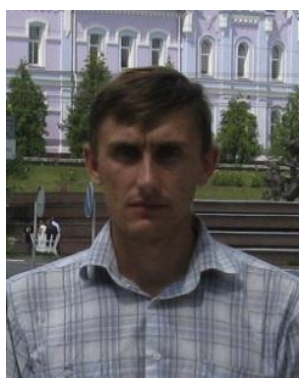

Alexey KOTLIAR (ORCID 0000-0001-7664-0395), PhD, Docent, Associate Professor at the Department of technology of mechanical engineering and metal-cutting machine tools of the Educational and scientific institute of mechanical engineering and transport of the NTU «KhPI», Kharkov, Ukraine.

Main directions of scientific research: enhancement of functional capabilities and an increase productivity metalcutting machines; multi-criteria optimization of technological processes and systems. 